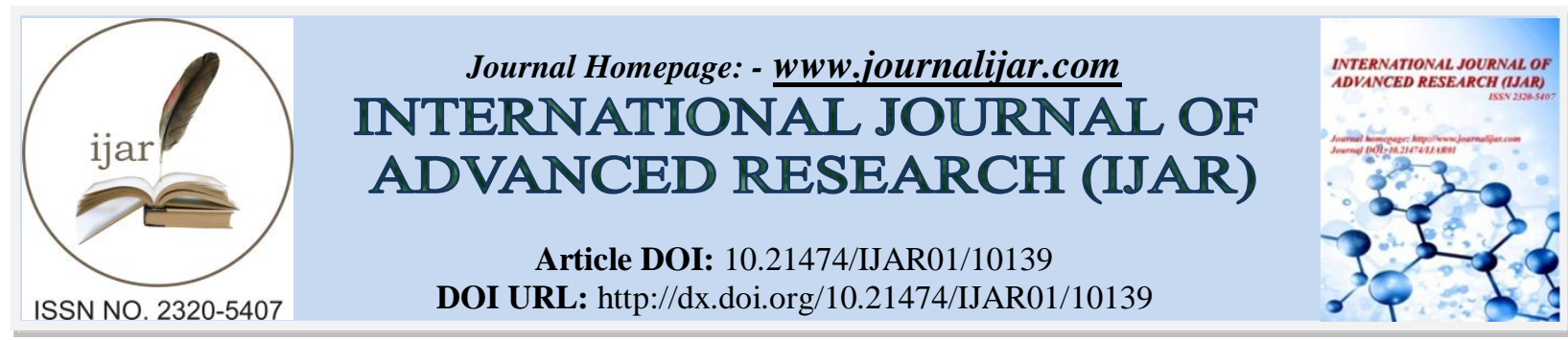

RESEARCH ARTICLE

\title{
ATTITUDE OF STUDENTS TOWARD PHYSICS: IT'S INFLUENCE TO THEIR ACADEMIC PERFORMANCE IN WEST POKOT COUNTY, KENYA.
}

Juma Joseph Murunga, Simiyu Kepher, Salome Awinja, Ezine Enos, Rose Kisaka, Beatrice Watiti, Ben Malesi, Wamalwa Daniel, Nalondo Phanus, Leaonard Wekesa, Kellways Nyamanga, Maurice Mwalo and Murrey Magut.

Med (Policy Planning And Management) Northwestern Christian University.

\section{Manuscript Info}

Manuscript History

Received: 01 October 2019

Final Accepted: 03 November 2019

Published: December 2019

Key words:-

Attitude, Perception, Chi-Square

Analysis, Personnel.

\section{Abstract}

Students' success in mathematics depends upon attitude toward physics. It also influences the participation rate of learners. In the last few years, that is 2011 to 2013 there was continuous fall in the performance of the subject of physics in secondary schools in West Pokot in the County. However this caused a lot of tension among the various stakeholders. The study's objectives were to; analyze the performance of students in physics in West Pokot County secondary schools in the years 2011, 2012 and 2013, identify the factors which determine students' attitude toward physics in secondary schools and examine the relationship between students' attitude toward physics and their academic performance. Respondents were selected through simple random technique. Since the purpose of the study was to investigate the effect of secondary school students' attitude toward physics on their academic performance in secondary schools, stakeholders constituted the sample. Data was collected using questionnaires and interview guide before being presented using graphs. The data was analyzed using Pearson Chi-Square analysis. Primary source and secondary source were also used to enrich the study. It was found that the number of students in the years 2011, 2012 and 2013 who had failed the physics subject were as follows: 205, 286 and 299 respectively. The majority were between ages of 15-17 years. Research revealed that parents' role, gender of students, teachers' remarks were the major factors determining the students' performance in physics. Further still, it was found that there was a significant relationship between students' attitude toward physics and their academic performance $\left(\mathrm{x}^{2}=70.002\right.$, df $=20, \mathrm{p}=0.000$ ) of students in secondary schools in west Pokot in Kenya. It therefore implied that students' attitude determines their academic performance in Physics. In the light of the above findings the study recommends that stakeholders at all levels should ensure that schools are well equipped with required resources and personnel to boost physics performance. Permission was obtained from the ministry of education West Pokot County, Kenya.

Copy Right, IJAR, 2019,. All rights reserved. 


\section{Introduction:-}

This chapter presents the background of the study, statement of the problem, purpose of the Study, Objectives of the Study, Research Questions, Significance, Justification and scope of the study.

\section{Background}

The background is subdivided into; Historical, Theoretical, Conceptual and Contextual The idea to study Physics in secondary schools started in Britain in 1850 by William Sharp, who left a job at Rugby School in 1850 after establishing Physics in the curriculum (Learly, 2004 and William, 2005). He established a model for Physics to be taught throughout all British Public Schools. In 1867, the British Academy for the Advancement of Physics (BAAS) published a report which gave way to the promotion of teaching of "pure science" and training of a "scientific habit of mind." A progressive education movement of the time by Layton (1981) supported the ideology of mental training through the sciences. Physics is difficult to students because it necessitates a lot of patience and persistence to understand. Analysts like Fleming (2012), argues out that Physics requires a lot of time because its study has little to do with brain power but a lot of staying power is required. In a general analysis of physics situation in schools in England, Osborne (1998) claimed that the subject of physics and physics courses at schools are only taken by students who do well and are not taken as incidental or additional subject. Indeed, among students in schools world over, physics is perceived as an elite discipline (Koballa, 1998 and Woolnough, 1994), which is viewed as conceptually difficult and only suitable for exceptionally talented and gifted students.

West Pokot County is found in the North rift part of Kenya. It consists of 50 secondary schools (1 private and 1 national school and 48 County and Sub County schools). The academic performance in physics for west Pokot County has been the worst in the North rift region and it has attracted attention of various stakeholders including government officials and parents. The mean score for 2011 was 6.3573; 2012- 6.3392; and 2013- 6.1247. A good number of schools have also been noted not to be offering the subject. This is due to the subject being optional whereby Biology and Chemistry have been made compulsory. These schools include; Kacheliba mixed, St. Catherine Chepnyal, St. Stephen Laikong, ELCK Chepkalit, Seker mixed, Riwo, St. Anthony of Padua Sina, St. Mary's Pserum and St. Augustine Chepkopegh. Some schools have alternating enrollments in physics whereby in some years have candidates while in other years miss candidates. These include; Fr. Leo girls, holy rosary girls, Keringet and Kabichibichi girls. Teachers in these schools noted that students' attitude was the major factor contributing to this continuous decline in academic performance

According to Von, Sophie, and Chamorro (2011), an attitude is an expression of favor or disfavor toward a person, place, thing, or event (the attitude object). Prominent psychologist Gordon Allport once described attitude as the most distinctive and indispensable concept in contemporary social psychology. On the other hand, Pistolle (2009) describes attitude as a person's perspective toward a specified target and way of saying and doing things. Morres (2005) defines academic performance as how well one does in school. Poor grades are considered bad academic performance and many athletes are forced to stop playing due to this. Academic performance according to Templenton (2009) refers to the outcome of education or the extent to which a student, teacher or institution has achieved their educational goals.

According to Ward, Howard, Stroker and Murray-Ward (2008), academic achievement is commonly measured by examinations or continuous assessment but there is no general agreement on how it is best tested or which aspect are most important procedural knowledge such as skills or declarative knowledge such as facts.

Ayala (2007) understands a student as a learner, or someone who attends an educational institution. In some nations, the English term or its cognate in another language is reserved for those who attend university, while a schoolchild under the age of eighteen is called a pupil in English or an equivalent in other languages, although in the United States and in Australia a person enrolled in grades $\mathrm{K}-12$ is often called a student. However, in its widest use, the concept is used for anyone who is learning, including mid-career adults who are taking vocational education or returning to university. These can refer to a change that is a result or consequence of an action or other cause. The concept can also refer to a result or change of something. Effect can equally refer to the power to produce an outcome or achieve a result, influence. This is a term that normally takes place in secondary schools, taking place after primary education and may be followed by higher education or vocational training. In some countries, only primary or basic education is compulsory, but secondary education is included in compulsory education in most countries (Warxt, (2007). On the other hand Secondary school can be used to mean a school which provides children with part or all of their secondary education, typically between the ages of 11-14 and 16-18, although this varies. It 
comes after primary school or middle school and may be followed by higher education or vocational training. The academic performance of secondary school students in physics is affected by their attitude toward the subject.

\section{Statement of the Problem}

In the last three years that is from 2011 to 2013 there has been a continuous fall in the academic performance of students in the subject of physics in secondary schools, in West Pokot. In Kenya, physics is taught for career reasons, engineering courses, medical courses and architectural courses. The government has tried to organize seminars and workshops to enhance on the skills of delivery for science teachers; through strengthening Mathematics and Science Subject Education (SMASSE). However, much as teaching physics in secondary schools is intended to achieve the above objectives, it has not been a success because a good number of students end up failing the subject. There are complaints from students and teachers concerning the study of physics, some students have reached an extent of not enrolling in physics; few of them like it and say that it is favorable.

The problem as stated above required empirical investigation, hence the purpose of the current study.

\section{Purpose of the Study}

The purpose of this study was to investigate the effect of secondary school students' attitude toward physics on their academic performance in West Pokot County in Kenya.

\section{Specific Objectives}

The specific objectives of this study were three:

1. To analyze the performance of students in physics in West Pokot County secondary schools.

2. To identify the factors which determined students' attitude toward physics in secondary schools

3. To examine the relationship between students' attitude toward physics and their academic performance

\section{Research Questions}

To address the purpose of this study, three research questions were developed to guide the study

1. What is the performance of students in physics in West Pokot County secondary schools?

2. What factors determined students' attitude toward physics in secondary schools?

3. What was the relationship between students' attitude toward physics and their academic performance?

\section{Significance}

The study may be useful in the following ways:

The study may establish the causes of poor performance in physics. This may enable teachers to find solutions to the above problems.

The study may provide information on students' attitude toward physics and their performance. Therefore, it may act as a basis for further research to academicians, scholars for further research and learners for form three and four. This may serve to bridge the gap in students' attitude and academic performance in physics.

The study may enrich the existing literature for the benefit of policy makers and other stakeholders in Kenya including district education board in west Pokot County.

Finally the study may also serve as a reference material for scholar education in Busoga University and other institutions of higher learning

\section{Literature Review}

Introduction

This chapter reviews the literature related to the subject under investigation in order to shed light on the subject and also provide a framework for investigation. It consists of a theoretical review, literature review in line with specific objectives of study, and conceptual framework. This chapter was concerned with the various opinions of different authors, consultants about the effect of secondary school students' attitude toward physics on their academic performance. 


\title{
Theoretical Review
}

This research was guided by two theories: The social learning theory (SLT) and All port's trait theory. However All port's theory was used throughout the study.

\begin{abstract}
Allport's trait theory
Allport discusses three basic concepts which make his theory so relevant to this study. These three concepts can be used to establish the external and internal factors which influence students' attitude toward physics. Allport's three trait levels are: Cardinal trait - the trait that dominates and shapes a person's behavior. These are the ruling passions/obsessions, such as a need for money and fame; Central trait - a general characteristic found in some degree in every person. These are the basic building blocks that shape most of our behavior although they are not as overwhelming as cardinal traits. An example of a central trait would be honesty; and Secondary trait characteristics seen only in certain circumstances such as particular likes or dislikes that a very close friend may know. Allport hypothesized the idea of internal and external forces that influence an individual's behavior. He called these forces Genotypes and Phenotypes. Genotypes are internal forces that relate to how a person retains information and uses it to interact with the external world. Phenotypes are external forces, these relate to the way an individual accepts his surroundings and how others influence their behavior. These forces generate the ways in which we behave and are the groundwork for the creation of individual traits.
\end{abstract}

Allport was one of the first researchers to draw a distinction between Motive and Drive. He suggested that a drive forms as a reaction to a motive, which may outgrow the motive as the reason for a behavior. The drive then becomes autonomous and distinct from the motive, whether the motive was instinct or something else. The idea that drives can become independent of the original motives for a given behavior is known as "functional autonomy." Allport gives the example of a man who seeks to perfect his task or craft. His original motive may be a sense of inferiority engrained in his childhood, but his diligence in his work and the motive it acquires later on is a need to excel in his chosen profession, which becomes the man's drive. Allport says that the theory "avoids the absurdity of regarding the energy of life now, in the present, as somehow consisting of early archaic forms (instincts, pre-potent reflexes, or the never-changing Id). Learning brings new systems of interests into existence just as it does new abilities and skills. At each stage of development these interests are always contemporary; whatever drives, drives now. Another example of functional autonomy is when the original motive of making money to buy goods becomes a drive, in which making money becomes an end in itself. Functional autonomy is thought to underlie obsessions and compulsions.

\section{The Social Learning Theory (SLT):}

Albert Bandura was used to guide this research. The Social Learning Theory was advanced by Albert Bandura in 1977. Bandura believed that direct reinforcement does not account for all types of learning. Bandura unfolds three concepts which determine the process of learning. First, people learn through observation, secondly, internal mental states are essential in learning, and third, the fact that something has been learnt does not mean that there is change in behavior (Kendra, 2012). These concepts are in line with students' attitude that is to say, students' attitude toward Physics depends on their observational learning, their internal mental states toward physics or an assumption that the fact of teaching physics daily in a class does not mean that students love it and are likely to perform well.

\section{Conceptual Framework}

Figure 2.1:- Conceptual Framework

Adapted Osgood, C.E, Suci, G., \& Tannenbaum, P. (1957). From the above conceptual framework, the independent variable (students' attitude toward Physics) refers the opinions of students toward Physics which could include; Physics being considered for classroom only, Physics as a difficult subject, Physics as impossibility in life, and Physics as a subject that cannot be scored. This breakdown provides an overview on how students in various schools perceive Physics. There are some factors which intervene between students' attitude toward Physics and in turn determine the end results/academic performance. These intervening variables were given as teaching methodologies, availability of textbooks, assessment mechanisms and stakeholders. The better academic performance depends on student attitude toward the subject in relation to the available resource and personnel. The students' academic performance is graded as excellent, very good, good, fair or poor basing on whether the intervening variables are positive or negative. When there is availability of textbooks, support from stakeholders and proper teaching methodologies then the academic performance in physics will be better. Lack of above will affect content delivery negatively leading to poor performance. When students' attitude toward physics is positive, then the 
subject will not be only for classroom use, hard or impossible but will be a friendly subject. This will in turn enhance better academic performance in the subject. For academic performance to be outstanding, students' attitude toward physics must be motivated through good assessment mechanisms and provision of support from all involved stakeholders and improved methods of teaching.

\section{Performance of Students in Physics at final exam}

Research carried out in South Africa shows that students, study Physics because they know it as an important subject in any field of science (Middleton, 1999). In addition, it also serves as a filter for entry into various career paths. Hammouri (2004) noted that the number of Physics students who took it on the higher grade between 1995 and 1997, dropped to about a half the number taking it on the higher grade between 2000 and 2004. To Robinson (2008), the concern lies with a small number of higher grade Physics students eligible for the study of science-based professions.

\section{Factors which determine students' attitude toward Physics}

The way Physics is represented in the classroom and perceived by students, even when teachers believe they are presenting it in authentic and context dependents entirely on the way it stands to alienate many students from Physics (Leoville, ferlinghetti, and Pekhonen, 2002). Representation of Physics in classroom stated by has a virtual relationship with findings that teaching methods determine students' attitude toward Physics. Muhammad and Shah also contend that the teaching methodologies determine students' attitude toward physics. However, as already stated earlier, this aspect of teaching methods is short of the internal motives of students inherited either from their parents or adopted from environments influence outside the school.

Girls are often discouraged from doing subjects like physics, claiming they are subjects for male students. So they drop it at high grade levels in greater numbers than boys (Madelleine, Mirriam, and Weinner, 2006). These findings also reflected that attitude toward Physics is developed in children positively from the infant level. However, talks about discouragement toward Physics development among female scholars. Allport's trait theory states that the drive forms one's motive and therefore as a cardinal trait among students is ignited by parents, they drive girls to have an imagination or motive that they cannot do physics because it is a hard subject. According to Allport, the strength of parents' influence on behavioral habits was reflected by functional autonomy. However, in certain communities such as West Pokot, there are also other factors that equally explain girls dislike for Physics. This study did not only look at parent-related factors but explored more about the other factors which make girls-children and boy-children have dislike for physics. Costello (2001) reported that students have a common perception that doing Physics is consistent with a male self-image and inconsistent with a female self-image." This self image is usually caused by the peer pressure (Meece, Glienke, and Samantha, 2005). This study sought to ascertain whether or not, peer pressure is one of the determinants of Students' attitude toward Physics which could in turn have negative implications on their academic performance.

Males are more inclined toward Physics than females on being the male dominated domain. It is found that at secondary school level most of the girls don't actively participate in Physics classes due to their negative attitude initiated by sex-role stereotypes (Meece, Glienke, and Samantha, 2005). All findings which claim that physics is more for male than female students ignore Allport's findings that in everything man does, there is an element of perfection. As female students go on with courage, they can finally become perfect in physics just like their counterparts -the male students. All professions requiring higher level knowledge of Physics are dominated by male community. Many barriers are there for the female students to have their career in Physics professions. Sometimes, female students show less confidence in Physics than their male counterparts (Arlene, 2001). Findings by Arlene would imply that basing on the language of parents toward Physics as they try to relate it to future career for females; girls develop negative attitude.

The attitude of prospective teachers toward Physics are so negative that many students cope and perceive Physics as those that can only be taught in class but of no help in day to day engagements (Akogu, 2011). According to Ball and Grass, students get such attitude because teachers only orient around classroom work while teaching. These are therefore termed as minor traits/central traits which can be ignored to perform well in physics. These findings therefore miss out the information that students must only stick on basic things which can influence their attitude toward physics. Majority of students who enroll for universities, including those who formerly performed well in Physics, reluctantly accept to study Physics as a degree course. As a result, they develop an imagination that Physics is not for classroom use and they get rid of it regardless of how much achievement it can make in their lives 
(Templenton, 2009). These findings clearly reveal that students lack the knowledge about the importance of teaching physics in secondary schools.

Negative attitude of Physics by parents are also transmitted to scholars. In societies, there is an attitude that if parents are not good at Physics, their children too will not be (Puscerak, 2010). Parents who were not good at Physics or are afraid of it are therefore often instrumental in reinforcing attitude that their children hold about Physics. Parents believe that physics ability is genetic and go on to tell their children that they don't expect them to succeed in it as they, themselves, were unsuccessful (Puscerak, 2010). Allport's trait theory in this respect enables the researcher to identify that even though parents' attitude can drive students to see physics as a hard subject, it is also possible for students to ignore their parents' drive and stick on secondary traits in order to develop positive attitude toward physics.

\section{Relationship between Students' attitude toward performance in physics}

Students' attitudes toward Physics play a crucial role in the teaching and learning processes because it affects students' achievement. The teaching method, support of structure of the school, family and students' attitude toward school affect the attitude toward Physics (Muhammad and Shah, 2008). These findings are reflected in Allport's trait theory under the secondary trait which includes someone's dislikes and likes. If analyzed using Allport's secondary trait, the use of good teaching methods stimulates positive attitude for students and they develop preference for physics in classrooms. However, this aspect cannot be relied on because teaching methodologies do little to consider cardinal factors which drive the students' attitude toward physics. Teaching methodology is just an external force yet attitude is more of an internal drive. This explains why the study sought to balance the internal and external forces which related to students' attitude toward physics and their academic performance. Positive attitude toward Physics lead to better academic performance in secondary schools. Attempt to improve students' attitude toward Physics at lower level provides base for higher studies. It also causes effect in achievement of Physics at secondary school level (Carroll, 2011). In other words, Carroll's findings reflect that students' attitude toward Physics are shaped from infant stages. Carroll's findings can be linked to Muhammad and Shah, (2008) who identify that one of the determinants of scholars' attitude toward Physics are the parents. Much as these findings are reflected in Allport's trait theory, they do not cover the adopted factors; for instance peer group influence at school is one of fundamental factors which determine students' attitude toward physics and their academic performance. This is why the study used Allport's trait theory which balances the external and internal factors.

It is the attitude of the student which contributes a lot in developing adaptability and applicability, later enhancing their academic performance in Physics (Karen, 2000). Just as Karen states, there are some students with positive attitude and they score highly in Physics. At the same time, there are others who do not have positive attitude and these end up performing poorly in final examinations. This is why Allport brings in the aspect of central traits that is to say factors which interrupt but do not matter a lot. It could be that students just do not have specific reasons but just hate physics and this makes them abscond from lesson. Students watch their parent's behavior and reaction to Physics and use this to justify their own performance (Demand Media, 2012). Parents view poor grades in Physics more acceptable than in other subjects. This keeps with the attitude of the American public that learning Physics is related to ability rather than effort (Lynn, 2009). This is directly inheritance or cardinal trait state by Allport in his Trait theory. However, Lynny's findings omit the fact that some factors may not be coming from home but from within school and Allport refers to these as secondary factors. The method used by lynn would not clearly explain how parents' attitude toward physics have greater influence on academic performance amidst other factors; hence the purpose of the current study. Furthermore, vicarious experience also defines students' attitude toward Physics; A "vicarious experience" is one in which students learn and develop through observing experiences and successes of others who share similar attributes as the students themselves (Loemberg, 1988). Students' self-efficacy attitude are boosted by watching others perform Physics tasks. If the learner observes someone with similar attributes as he/she succeed in an activity, it contributes to him/her creating the belief that he/she is also capable of accomplishing the task with the same degree of success (Noble, 2011). These are known as central traits in Allport's trait theory. Much as students' can adopt their attitude through watching others' behaviors toward the subject, there are still more central traits which are not expressed in this study and can be investigated through this research imitative.

In addition to the above, if a learner assumes a high degree of similarity with a peer, then the peer's successful experiences are absorbed by the learner, and the students is then persuaded that this success is possible for him/her as well (Noble, 2011). Students who are uncertain of their own capability in Physics are more susceptible to being influenced vicariously than those who are set in their attitude toward their capability in Physics. Though learning 
through observing others might not be as direct and strong as learning through one's own experience, vicarious experience has a significant effect on performance. The source that is considered as the most common contributor to development of self-efficacy attitude is verbal persuasion (Parjas and Graham, 2008). Studies by Middleton and Spanias (2009) show a positive correlation between attitude, positive experiences, attitude and achievement in physics. Poor attitude toward Physics has often been cited as one factors that has contributed to lower participation and success of girls in Physics" in academic institutions. Interest and attitude in the subject are the special predictors for the students' participation and success in the subject (Hamlison and Whipple, 2012). These findings lack specific explanations on how the poor attitude toward Physics influences students' academic performance. The methods used to obtain data could not probe for more knowledge on the reasons as to why students are fond of negative attitude toward physics. Not only that, but the study concentrated on only girls forgetting that there are also boys who fail to participate at the same time succeed in physics. Therefore it is the sole purpose of the current study to investigate the factors that contribute to lower participation and success of both boys and girls in physics. Students, who believe that sciences particularly physics are important, are more likely to feel positive about it and tend to value them more than those who do not (Middleton and Spanias, 2009). Middleton and Spanias' findings lack an explanation on how students can be made to develop a feeling that Physics is important. The reason as to why students' negative belief comes toward physics could have been eternal of internal and not until this is clearly brought out, Allport's central trait approach which treats some factors as very minor continued to have a greater influence in the study. On the negative perspective, disengagement in Physics leads to reducing the range of higher education courses available to students in addition to limiting their capacity to understand life experiences through a science perspective (Hamlison and Whipple, 2012).There are many challenges that typify the transition from childhood to adolescence including physical, cognitive, social and school changes. During this time adolescents are faced with decisions regarding their commitment to school and learning. As schools and classrooms are inherently social places, it is likely the peer group is a significant influence on adolescent achievements, attitude and behaviors (Ryan, 2000). In the study, Students' attitude showed how their own efforts influence achievement at Physics, Sullivan. (2006) found positive responses to school Physics learning opportunities were inhibited by a combination of direct and indirect pressure from peers not to try hard in school, rather than lack of confidence or lack of success. The need for adolescents to feel a sense of belonging and acceptance, can often lead to conforming to peer demands which censure achievement and success at school. Sullivan believes classroom culture may be a much stronger determinant of engagement than the curriculum, pedagogy or teacher experience.

\section{Methodology:- \\ Introduction}

This consists of the research design, area of study, study population, data collection methods, sampling and sampling techniques, ways of presenting and analyzing findings, Interpretation of findings, and ethical considerations.

\section{Research Design}

A research design is a systematic plan to study a scientific problem. The design of a study defines the study type as descriptive, correlation, semi-experimental, experimental, review, meta-analytic and sub-type for example, descriptive-longitudinal case study, research question, hypotheses, independent and dependent variables, experimental design, and, if applicable, data collection methods and a statistical analysis plan (Gorard, 2013). The researcher used the survey research design. This is whereby the researcher interacts with the respondents in the field. The survey research design is also called field research. A Descriptive Survey is a type of research design often used to assess thoughts, opinions, and feelings (Shaughnessy, Zechmeister, and Jeane, 2011). The research approach enabled the researcher to obtain authentic data from respondents. The study was conducted in 32 secondary schools in West Pokot. Sampling is concerned with the selection of a subset of individuals from within a statistical population to estimate characteristics of the whole population (Dillman, Smyth, and Christian, 2009). West Pokot County consisted of 37 schools that were offering physics.

Table 1.1:- Number and sample size for the various categories of respondents

\begin{tabular}{|l|l|l|l|}
\hline Population category & Total number $(\mathbf{N})$ & General sample $(\mathbf{n})$ & Sample per school \\
\hline Head teachers & 37 & 32 & $32 / 32=1$ \\
\hline Students & 1500 & 306 & $306 / 32 \approx 10$ \\
\hline Teachers & 37 & 32 & $32 / 32=1$ \\
\hline Board of Management & 256 & 148 & $148 / 32 \approx 5$ \\
\hline
\end{tabular}




\begin{tabular}{|l|l|l|l|}
\hline DEO & 1 & 1 & 1 \\
\hline
\end{tabular}

NOTE: the sample size of students for each school was 10 giving a total sample of 320 for the 32 schools as opposed to 306. However, the researcher used a sample of 306 because there were some schools which did not have ten physics students. Many had less than 10, others had 5 to 6 and some 13 and above. Therefore, the differences in numbers helped the researcher to balance the sample size among selected schools. In a simple random sample (SRS) of a given size, all such subsets of the frame were given an equal probability. This minimized bias and simplified analysis of results. The variance between individual results within the sample was a good indicator of variance in the overall population, which made it relatively easy to estimate the accuracy of results (Moore and McCabe, 2014).

The reason for using this technique is because it treats each element in a specific category with similar chances of being selected; hence it can be appropriately used after stratified sampling technique. This technique was used to select individual respondents from categories of physics teachers and students.

The study employed questionnaire as the main data collection instrument.

The randomly distributed Questionnaires containing closed ended Head teachers Physics teachers and Board of Management (BOM). Questionnaires were used because questions were arranged according to specific objectives of study hence study oriented, they were distributed to many people and responses obtained in the shortest time and it gave the respondent enough time to fill in the answers required. The questionnaire also included distant respondents for it was well planned and focused (Walter, 1989). Items were scored in Likert scale as strongly agree, agree, undecided, strongly disagree, and disagree. An interview Schedule guide is a list of topics, themes, or areas to be covered in a semi structured interview. This is normally created in advance of an interview by a researcher and is constructed in such a way as to allow flexibility and fluidity in topics and areas that are to be covered, the way they are to be approached with each interviewee (Mason, 2013). The researcher also used an interview guide to collect data from the District Education Officer. The interview guide enabled the researcher to; freely interact with respondent, thereby probing for detailed information about the research problem and providing back-up information especially to cover gaps left by responses given in questionnaires. Hhe focus group discussion was done on by stm

The validity and reliability was tested by the pilot study. In science and statistics, validity is the extent to which a concept, conclusion or measurement is well-founded and corresponds accurately to the real world (Rich, 2011)

The validity of questions were determined by the researcher using the following formula by (Rich, 2011).

$\mathrm{CVI}=\quad$ Number of items judged by both judges as relevant

Total number of items in the questionnaires

The validity of the questions was determined by scoring the questions on a scale of very relevant $=4$, relevant $=3$, some what relevant $=2$ and not relevant $=1$.

The result was CVI (Content validity test) of 0.8975 . Since CVI was greater than 0.5 meaning that the questions in the study were valid. Analysis of data was done to inspect, clean, transforming, and modeling data to discover useful information, suggesting conclusions, and supporting decision making (Hollerstein, 2008). The data was analyzed using SPSS. This was used to work out percentages. Pearson's Chi Square was used to test the relationship among variables. Qualitative books, journal articles, internet material (such as articles, papers), reports, research papers and interviews of findings were obtained and presented descriptively to back-up or complement the quantitative data.

\section{Findings and Discussion:-}

Findings about performance of students in physics during National examinations for the three years showed unpleasing results. The study also established that the number of Boys consisted of the highest number of students who did physics and their performance in those last three years had been promising compared to other secondary schools in the distribution.

Table 4.2:- West Pokot County students' annual performance in physics

\begin{tabular}{|l|l|l|}
\hline YEAR & Total number of students per year & PERCENTAGE (\%)
\end{tabular}




\begin{tabular}{|l|l|l|l|}
\hline & & PASS & FAIL \\
\hline $\mathbf{2 0 1 1}$ & 629 & 67 & 33 \\
\hline $\mathbf{2 0 1 2}$ & 645 & 56 & 44 \\
\hline $\mathbf{2 0 1 3}$ & 740 & 60 & 40 \\
\hline
\end{tabular}

Source: primary data

The pattern of performance according to the table reflects unpredictable performance of students in physics. The findings established that parents influenced students' attitudes towards physics performance in their learner's. The opinion given also depended on educational background $\left(\chi^{2}=75.475, \mathrm{df}=20, \mathrm{p}=0.000\right)$ of the respondents. The results indicated that there was a strong relationship in students' attitude being influenced by parents. Students showed concern toward remarks used by parents toward physics. On the positive side, parents' views toward physics were as follows; educated parents' advice children to do all sciences reasoning that because of technological order, physics carries a high percentage of knowledge in society. Besides, some parents noted that if students can attempt mathematics, they should equally do physics. In addition parents remark that physics makes one rich in future because they get a lot of money when employed in scientific fields. Finally, parents say that students who do physics think critically and cannot be challenged by life situations. It was established that many parents raise bad comments toward physics which reduce and terminate students' positive attitude toward the subject. Findings revealed that parents look at the general view whereby few people are doing science and use it to justify the cause for not doing physics. Besides, some parents with low social economic statuses discourage students from doing physics claiming that the subject can lead to enrollment of very expensive courses whose costs are unaffordable. Peer group is a social group of people who have similar interests, age, background and social status. The findings revealed that Peer group influence is affected or changed a person's belief or behavior due to similar interests and social sta

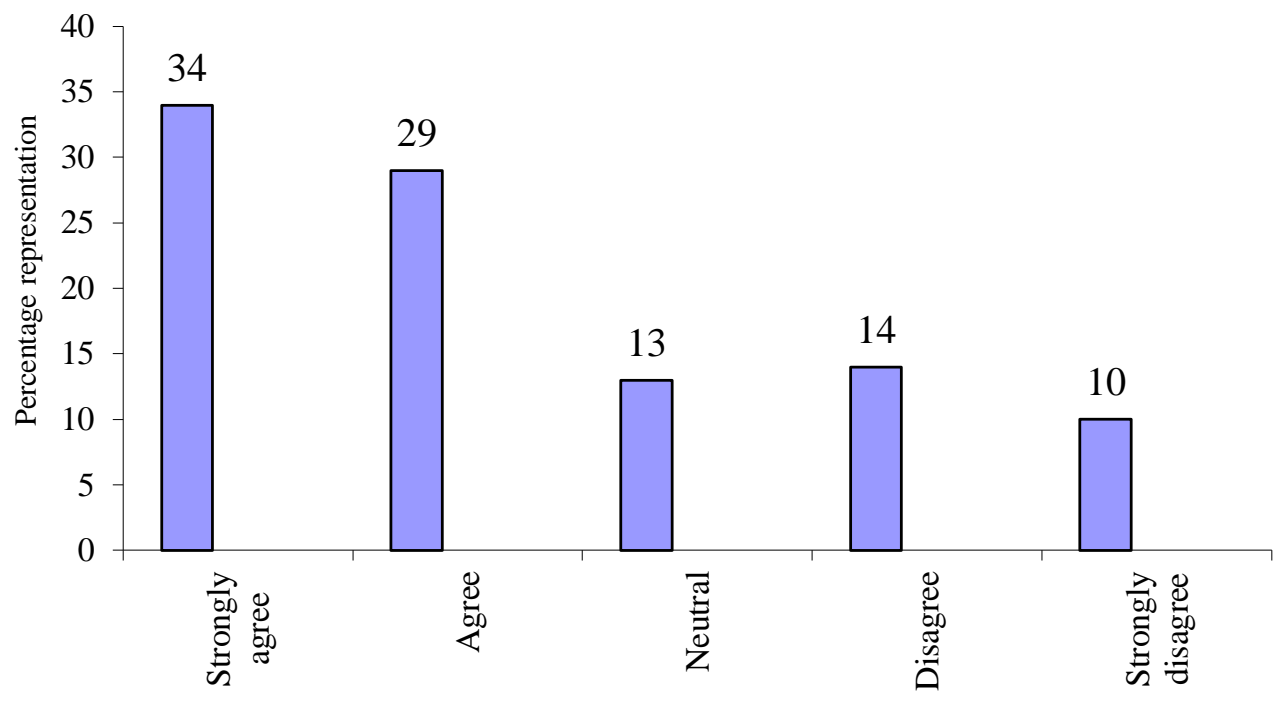

Opinion of respondents

Source: primary data.

The study established that per groups influenced physics performance in many learning institutions. The observed difference in the opinion was statistically significant and depended on age $\left(\chi^{2}=59.493\right.$, $\left.\mathrm{df}=12, \mathrm{p}=0.000\right)$, religion $\left(\chi^{2}=26.206, \mathrm{df}=12, \mathrm{p}=0.000\right)$ and marital status $\left(\chi^{2}=82.959, \mathrm{df}=12, \mathrm{p}=0.000\right)$ of the respondents. The results show that there is a strong relationship between students' attitude and peer group influence. The respondents who do not agree with this opinion represent a group of people who cannot be influenced by peer pressure hence are self driven. Results from the interviews indicated that chances were very high that students influence each other to either do or not do physics. In discussions held, students stated some of the ways in which their peers describe physics; some say physics is a hard subject, others say it is simple, some reflect that Physics is the best among all science subjects; it is simple and they regret dropping it and other friends say it is the hardest subject in the world. Out of these remarks come positive and negative perceptions toward physics. Negative remarks create an environment whereby students can never be encouraged to offer physics. Some students even regret having dropped the subject after discovering that they were in a wrong company. However, all peers with positive attitude will always speak 
about the best career opportunities in the subject, dignity a person who does physics can command in the community, un-competitiveness of science jobs, ability to become an engineer and other good things to encourage other students develop positive attitude toward physics. The findings established that gender defined as socially constructed and culturally variable concept which determines the roles that men and women play in their daily lives in a particular context. The aspect of gender in relation to students' attitude toward physics was also reflected in comments raised by parents about physics. Parents, according to findings from discussions have an assumption that physics is a subject for male students and that their female counterparts cannot afford calculations embedded in the subject, which according to the DEO is a misconception. To the DEO, anybody can afford to do physics and if physics is regarded as the most difficult subject, it can be made simple by modifying the language used by parents and teachers toward the subject.

\section{Perceptions of teachers in class rooms determine students' apperception toward physic}

Figure 4.10:- Opinion of respondents toward teachers' perception in class

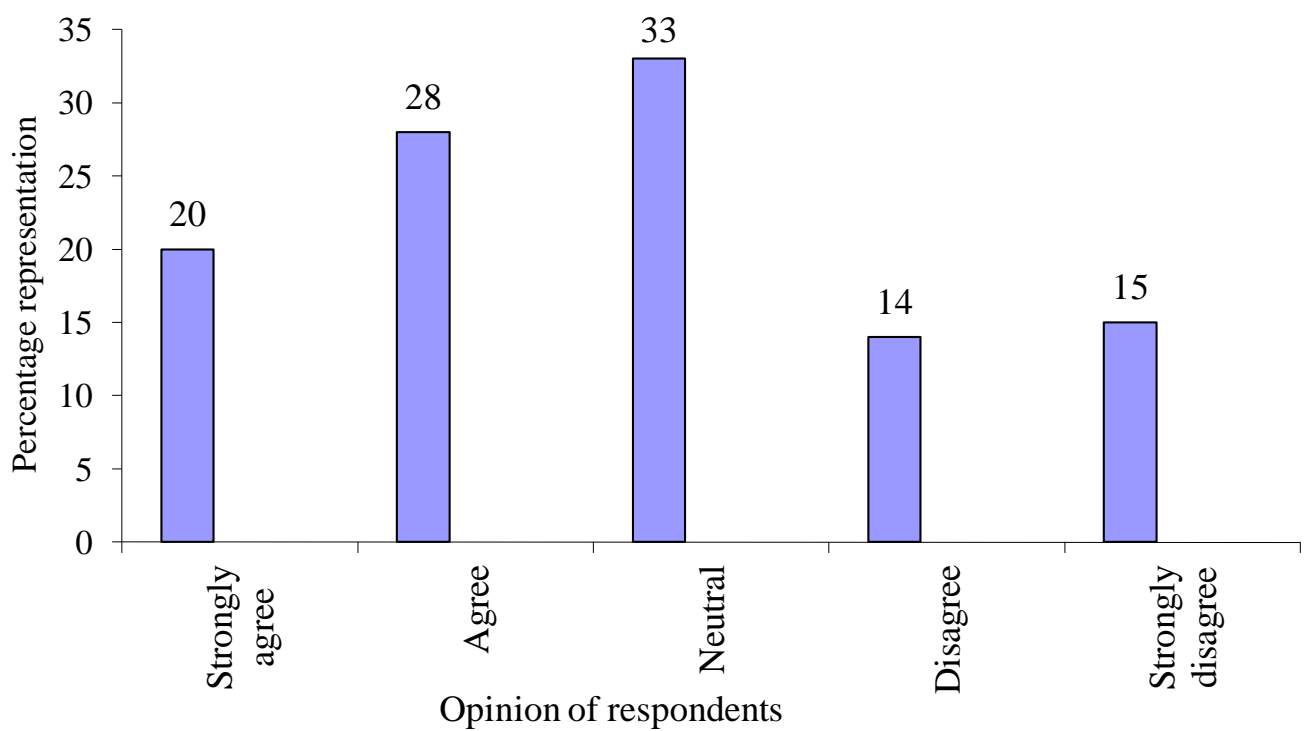

Source: primary data

The findings from above graph established that perceptions of teachers influence student attitude toward physics The opinion of respondents toward perception of teachers in classrooms influence students' attitude toward physics depended on the age $\left(\chi^{2}=54.723, \mathrm{df}=12, \mathrm{p}=0.000\right)$ and religion $\left(\chi^{2}=37.380, \mathrm{df}=12, \mathrm{p}=0.000\right)$ of the respondents. There was a strong relationship between perception of teachers in classrooms and students' appreciation toward physics. This implies that negative comments given by teachers adversely affect students' performance thus justifying the failure in physics. During discussions, students were asked to state teacher's comments about physics while in class and the various responses received were; teachers advised students to read ahead to get room for asking questions and understanding difficult topics well. They encourage students to have revision books in order to summarize notes and ease revision Findings therefore revealed that in class, teachers rarely use negative remarks toward physics and this makes some students continue enjoying the subject.

\section{Resource availability at school and students' attitude toward physics}

Resource is defined as a productive factor required to accomplishing an activity. Resource availability is being accessible to the required facility so as to achieve the desired goal. 
Figure 4.13:- Opinion of respondents toward resource availability

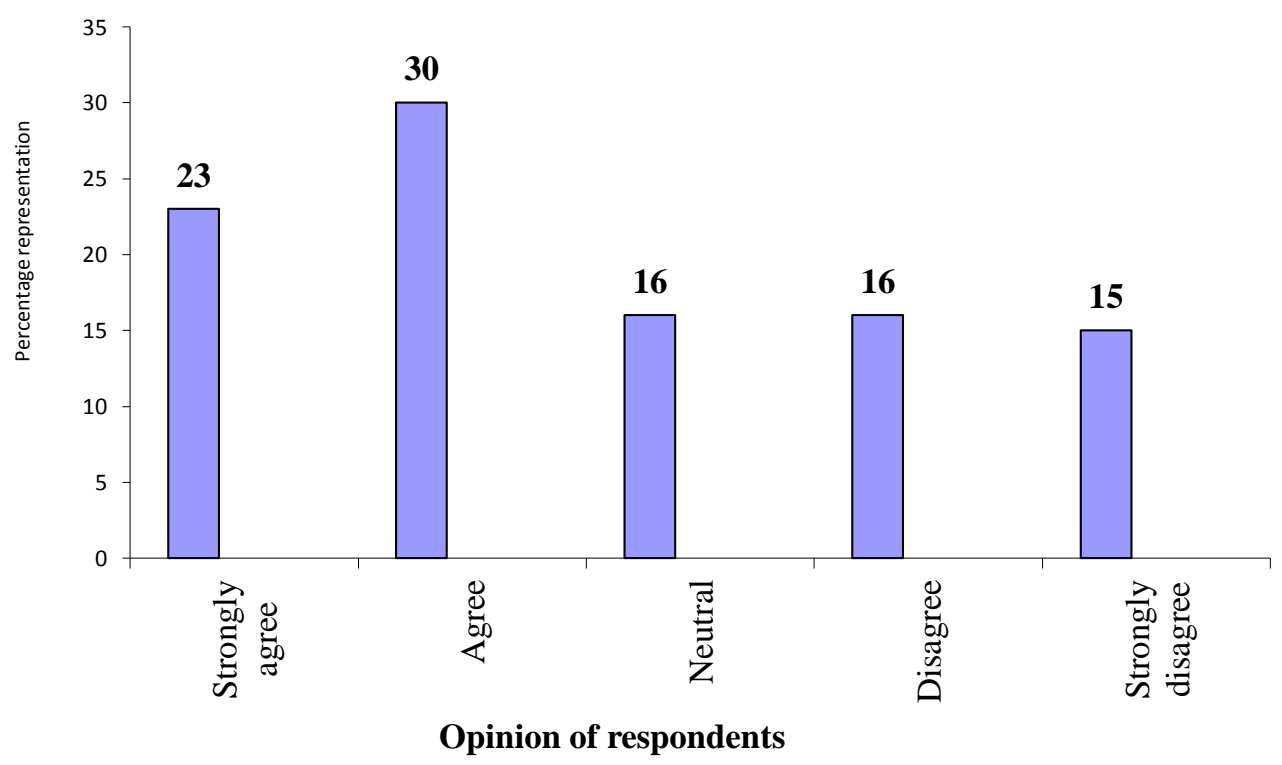

Source: primary data

Besides community perceptions, resource availability is yet another factor which explains the determinants of students' perception toward physics.

From the above graph it is revealed that 53\% (23\% strongly agreed and 30\% agreed) of the respondents were in agreement with the opinion that resource availability determines student attitude toward physics in West Pokot County. This implies that most schools are not well equipped with necessary resources for students' use. This justifies the poor performance by students. Whereas $31 \%$ (15\% strongly disagreed and $16 \%$ disagreed) of respondents were in disagreement implying that good performance can still be achieved through improvisation of little available resources. It is also implied that schools that offer physics do not have enough resources hence making students perform poorly in national examination. While discussing factors which create negative attitude toward physics, students stated that having a science laboratory without equipment for practical tests discourages them at times. Despite this some self motivated students still pass physics examination yet their laboratories are not fully equipped

Figure 4.14:-Opinion of respondents toward economic status of parents.

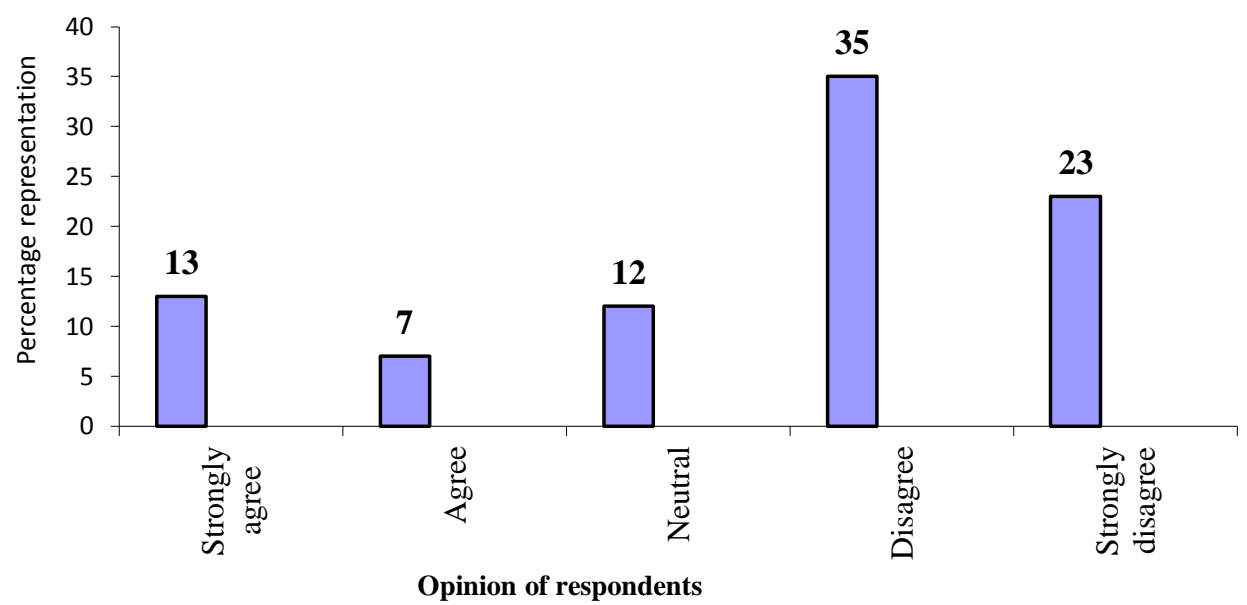

Source: primary data

The results from the above graph showed economic status of parents as one of the factors which determine students' attitude toward physics. The graph revealed that 20\% (13\% strongly agreed and $7 \%$ agreed) were in agreement with 
the opinion that parents' economic status influences students' attitude toward physics. Majority (58\%) of the respondents were in disagreement (23\% strongly disagreed and 35\% disagreed) with the opinion. This justifies that a student can still pass in physics irrespective of parental economic status. $12 \%$ of the respondents were not certain. Similar to these findings, when stating parents' comments toward physics, some parents claim that all science courses are very difficult and that for one to pursue it, he/she must have money to purchase apparatus as well as to pay for university fees. Remarks showed by students from parents indicated that some parents just fear the costs involved in studying science courses. As a result, they encourage their children to study arts based courses. Further still, due to lack of financial abilities, parents are not able to take their children to schools with well established science laboratories because of costs attached in school fees and other requirements. It was then justified that the following factors strongly affect student attitude toward physics: parental influence, peer group influence, student gender, perception of teachers, community perception, gender discouragement from relatives, generic factors and resource availability whereas economic status of parents does not necessarily affect students' attitude toward physics.

The positive attitude influences students to perform well in physics subject. Those students with negative attitude tend to perform poorly. Findings by DEO were in line with some findings obtained from discussions with students when they were stating factors which influenced them to do well in physics. In various discussion groups, students stated that the pass word to doing physics is having positive mind toward it. Students who do physics marked that positive attitude toward physics is the basis for students' performance. With positive attitude, students form discussion groups, go in groups to consult teachers about topics they never understood and they also go to science laboratories to perform practical experiments regularly. The findings implied that most students with positive attitude toward physics comply with any situation and make required adjustments to ensure that physics is not difficult hence score highly in examinations. A discussion held on factors which create student's dislike for physics revealed that utmost, many students start very well in form one without being counseled about the complications ahead of the syllabus. At one point in the course of running the syllabus, students encounter calculations and loose hope for better performance in the subject. Consequently, they fail to adjust their respective approaches and maintain the negativity that comes in their mind which culminates into poor academic performance. Results from the study revealed $23 \%$ of the respondents were in agreement with the opinion that girls attitude toward physics influenced their performance whereas $56 \%$ of the respondent were in disagreement with the opinion (Table 4.3). This implies that girls can multitask that is do various activities and still perform better than boys. Sparing more time in physics practice does not necessarily reciprocate the performance in exams. Some students spent few minutes studying but still pass highly than those who spent more hours studying the subject. The opinion given by respondents from different age class $\left(\chi^{2}=41.902, \mathrm{df}=12, \mathrm{p}=0.00\right)$ and from the different religion $\left(\chi^{2}=48.033, \mathrm{df}\right.$ $=12, \mathrm{p}=0.000$ ) was statistically significant. One of the major factors in findings from discussions with students was the fact physics requires a lot of time to concentrate because each topic in the syllabus is practical. All students involved in discussions emphasized that the only way to love physics is to give it enough time for concentration. Besides, students also emphasized that all topics in physics are practical and they argued that a student can hardly revise and understand concepts in physics if they are not in science laboratories. Students also emphasized use of electronic learning so as to understand some complex concepts better.

\section{Conclusions And Recommendations:-}

There was still poor performance in physics on girl's academic performance. Conclusively, the study identified that most of the factors which determine students' attitude toward physics act in turn with each other to influence the positive or negative attitude. Parents influence, peer influence, resource availability and gender were termed as phenotypes or external factors which enter into the mind of a student and determine the way he or she reacts toward physics. The study concluded that factors such as hatred for the physics subject, heeding to negative remarks by friends, failure to have self confidence, among other factors hinder students' academic performance mainly through making students reluctant to form or join discussion groups, they even fail to do assignments. This finally traps students in a situation whereby they cannot remember concepts when they sit for examinations which results into poor performance and continuous hatred for physics

Since the academic performance in physics is still low, the Kenya National Examination Council should do as much as it can to reduce on the pass mark so that even weak and unmotivated students can come up and strengthen for better performance. The stunted performance in physics must be perceived by policy makers that there is need to change policies and ensure that students, at any cost perform well in the midst of great challenges. To avoid stagnation in performance, teachers should organize internal and external seminars as a way of improving teaching 
methodologies and making students pass physics in the incoming years. Teachers should were to be organizing learner centered inter-schools Physics contests to enable students to compete and learn favorably. Parents need to develop positive attitude toward physics and also encourage their children to like the subject basing on its benefits especially in the job market. The gender of students was not be seen as a reason to deny students education. In fact parents must provide resources to male and female students equally.

Teachers were to be making always positive remarks about physics because they are the key stakeholders in determining students' attitude toward the subject and Stakeholders at all levels were to be contributing toward construction of science laboratories in all secondary schools to boost the morale of students toward physics.

Students should always form good discussion groups which dwell on practical work and with need to consult teachers in case of difficulty rather than fearing teachers of physics. Government ought to initiate a policy that provides for free education for all students who do physics as a way of motivating other students to like the subject and also to enable parents who view courses resulting from physics as expensive, to continue educating their children.

Teachers were to train students on question approach because it was cited as one of the obstacles leading to poor academic performance even among students with positive attitude toward the subject and that could enable them not Punic when they enter examination room because it was as easy to pass physics examination as it was to other subjects. Revision groups were to be paramount and most preferably in laboratories because physics was much of more experimental than theoretical. Benchmarking for science congress were to be always attended to as a school irrespective of gender.

\section{References:-}

1. Akogu, A. D. (2011). Teachers Attitude on Factors influencing the Teaching of Physics. Abuja: Niger State College of Education. http://www.iiste.orgRetrieved 19 ${ }^{\text {th }}$ Dec 2013

2. Al-Karaj. (2012). Islamic Physics. Walden: Walden Press.http://dx.doi.org/10.5402/2012/368634.Retrieved $13^{\text {th }}$ January 2014

3. Allen, D. (1997). Ageneral View of Physics before 30000 B.C, Where did Physics start? Newyork: Learning Unit, University of Leeds http://en.wikipedia.org/wiki/Vannevar_Bush. Retrieved $4^{\text {th }}$ jan 2014

4. Arlene, H. (2001). Remembering the Child on Equity and Inclusion in Physics and Physics Classrooms. Applied Research Centre.

5. Asale, B., and Adetunde, A. L. (2009). Comparative Performance of Day and Boarding Students in secondary school Physics. Navrong: Department of Physics, University of Mines and Technology, Tarkwa Ghana.https://www.academia.edu Retrived on $10^{\text {th }}$ Dec. 2013

6. Brains, Willnat, manheim, and Rich. (2011, March 10 ${ }^{\text {th }}$ ). Emperical Political Analysis. Validity , p. 2http://www.faculty.psci.vt.edu/brians. Retrieved on $12^{\text {th }}$ April 2014,

7. Brown, G. (2004). How Students Learn, A supplement to Rutledge Falmer Key Guides for Effective teachingin Higher Education Serries. Rutledge Falmer Key Guides for Effective teaching in Higher Education Serries.

8. Carroll, C. (2011). Evaluation of the University of Limmerick Physics Learning Centre. Limerick: University of Limerick.

9. Cheng-sun, R. (2009). Women's self-efficacy attitude in physics and science.

10. University of Southern Carolna.

11. Demand Media. (2012). Classroom Behavior Management, How to apply Behaviorism in Classroom. Demand Media.Inc.

12. Dillman, D. A., Smyth, J. D., and Christian, L. M. (2009). Internet, Mail and mixed-mode surveys. San Francisco: Jossey-Bass. http://eu.wiley.com/WileyCDA/WileyTitle/produc Retrieved on $7^{\text {th }}$ February 2014

13. Fleming, G. (2012). Why Physics is Difficult. New York: New York Times Company.

14. Francesca, A. (2010). Methods of Collecting Data; Interviews and Questionnaires in Practice. European Global Oral Health Indicators development Project.

15. Gorard, S. (2013). Research Design. London: sage Publications.

16. Hamlison, A. T., and Whipple, A. D. (2012). Individual Differences; Gender Equity And Schooling. US Universities http://www.encyclopedia.com/topic/Individual_Differences. Retrieved on $10^{\text {th }}$ November 2013

17. Hollerstein. J. ,(2008, April $\left.13^{\text {th }}\right)$. Quantitative data cleaning for large data bases. Data Analysis , pp. 3-6. www.webcrawler.com/ Investopedia. (2012). Systematic Sampling. InvestopediaULC. Retrieved on $8^{\text {th }}$ October 2013 
18. Karen, B. J. , (2000). Block Scheduling with a Physics Perspective. Illinois: Universityof Illinoiswww.ctserc.org/library/bibfiles. Retrieved on $6^{\text {th }}$ February 2014

19. Kendra.C., (2012). Social Learning Theory; An Overview of Bandura's Social Learning Theory. New York: New York Times Company.Retrieved on $19^{\text {th }}$ March 2014

20. Kevius, B. (2012). History of Physics. Buffalo University Press.Retrieved on $13^{\text {th }}$ April 2014

21. Kress. (2014, May 07). Introduction to Research. Unit 3: primary and Secondary sources of data , pp. 3-5.

22. Leoville, B., ferlinghetti, L., and Pekhonen, O. , (2002). Students' Attitude of Physics in classroom.

23. Lynn, G. (1999). Challenges of Education, National Advisory Committee on Creative and Cultural Education. No publication.

24. Madelleine, A., Mirriam, D., and Weinner, G. , (1989). Educational Reforms and Gender Equality in schools. Manchester: Equal Opportunities Commision.

25. Mason, J. (2013, December 12). Interview Guide. Interview Guide , p. 2. gdcreport.com/pdf/Interview_Memoranda.pdf Retrieved on $13^{\text {th }}$ December 2013

26. Mellenbergh, G. (2008). Tests and Questionnaires: Construction and administration.Washngton: Kessel publishers.

27. Moore, D. S., and McCabe, P. G. (2014, April $12^{\text {th }}$ ). Introduction to practice of statistics. Simple radom sampling, p. 6.

28. Muhammad, S. F., and Shah, S. Z. (2008). Students' Attitude toward Physics, Pakistan Economic and social Revew Volume 46 No. 1. Lahore: University of Punjab.

29. Noble, R. , (2011). Physics self Efficacy and African American Students: An examination of two models of Success, Journal of African Males in Education.

30. North Carolina Agricutural and Technical State University.

31. Parjas, F., and Graham. (1999). Self-efficacy, motivation constructs, and Physics performance of entering middle school students. Contemporary Educational Psychology. No publication.

32. Phelan, C. , and Wren, J. (2014, March 6 $\left.{ }^{\text {th }}\right)$. Exploring reliability in Academic Assessment. Reliability and Validity of academic research, p. 2.

33. Puscerak, R ., (2010). Self Theories, Growth Mindset and Fixed Mindset. No city: No Publication.

34. Resnik, D. (2011, Dec 8). What is Ethics in Research and why is it important? Ethical considerations, p. 9. researchethics.istss.org/ Retrieved on $2^{\text {nd }}$ May 2014

35. Robert, M. (2014, 04 7). Survey Methodology. Stratified sampling , pp. 1 -6. www.essex.ac.uk/courses/default.aspx Retrieved $2^{\text {nd }}$ February2014

36. Shaughnessy, J., Zechmeister, E., and Jeane, Z. (2011). Research methods in psychology. New york: McGrawHill.

37. Templenton, J. , (2009). Physics in Africa: Challenges and Opportunities, Developing Countries' Strategies' Union. Yaounde: University of Yaounde, Cameroon.

38. Von, S., Sophie, H., and Chamorro, B. (2011). the hungry mind: Intellectual Curiosity is the third pillar of Academic perfromance, Achievement after transition of first grade. Washington Dc: Journal of applied Developmental psychology.

39. Wang, M., and Halcombe, R. (2012). Adolescent's Attitude of school Environment,Engagement and Academic Achievement in Middle school American Educational Research Jurnal. New York: American Educational Research Association.

40. Ward, A., Howard, W., Stoker, W., and Murray-Ward, M. (1996). The Hungry mind: Intellectual Curiosity is the third pillar of Academic performance. London: Perspecitives on psychological science. www.essex.ac.uk/courses/default.aspx. Retrieved on $2^{\text {nd }}$ Feb 2014. 